\title{
LETTERS
}

\section{Quick and easy methods for "clean-catch" urine samples}

We read with interest the article by Hudson and colleagues on urinary tract infection in children. ${ }^{1}$ As clinicians working in rural and remote locations with limited staff and limited experience in invasive urine collection in children, we have successfully used a clean-catch urine collection method developed by Herreros Fernández and colleagues. $^{2}$ The technique, derived from methods used for patients with bladder dysfunction, begins with breastfeeding/ formula feeding the infant, followed by holding the child upright with legs dangling. After cleansing external genitalia, gentle suprapubic tapping (100 taps/min) is alternated with lumbar paravertebral massage for 30 seconds and repeated until micturition begins. ${ }^{2}$ The method is most successful in infants less than 90 days old but can be used in those who are up to six months of age. ${ }^{3}$

We are planning to attempt a recently published alternate manoeuvre, the QuickWee method, for infants up to 12 months of age. ${ }^{4}$ We believe these simple yet effective methods will save time and aggravation for clinicians who require urine collection in patients where invasive testing is unavailable or not indicated.

\section{Zahra N. Jaffer MB ChB \\ Brenda Muselius MD}

Family physicians, Weeneebayko General Hospital, Moose Factory, Ont.

- Cite as: CMAJ 2017 May 23;189:E731. doi: $10.1503 / \mathrm{cmaj} .733101$

\section{References}

1. Hudson A, Romao RLP, MacLellan D. Urinary tract infection in children. CMAJ 2017;189:E608.

2. Herreros Fernández M, González Merino N, Tagarro García A, et al. A new technique for fast and safe collection of urine in newborns. Arch Dis Child 2013;98:27-9.

3. Labrosse M, Levy A, Autmizguine J, et al. Evaluation of a new strategy for clean catch urine in infants. Pediatrics 2016;138.pii: e20160573.

4. Kaufman J, Fitzpatrick P, Tosif S, et al. Faster clean catch urine collection (Quick-Wee method) from infants: randomised controlled trial. BMJ 2017;357:j1341.

Competing interests: None declared. 